IZA DP No. 8928

Electrification and Educational Outcomes in Rural Peru

Rosamaría Dasso

Fernando Fernandez

Hugo Ñopo

March 2015 


\title{
Electrification and Educational Outcomes in Rural Peru
}

\author{
Rosamaría Dasso \\ International Food Policy Research Institute
}

Fernando Fernandez

Universitat Pompeu Fabra

Hugo Ñopo

Inter-American Development Bank

and IZA

\author{
Discussion Paper No. 8928 \\ March 2015
}

\author{
IZA \\ P.O. Box 7240 \\ 53072 Bonn \\ Germany \\ Phone: +49-228-3894-0 \\ Fax: +49-228-3894-180 \\ E-mail: iza@iza.org
}

\begin{abstract}
Any opinions expressed here are those of the author(s) and not those of IZA. Research published in this series may include views on policy, but the institute itself takes no institutional policy positions. The IZA research network is committed to the IZA Guiding Principles of Research Integrity.

The Institute for the Study of Labor (IZA) in Bonn is a local and virtual international research center and a place of communication between science, politics and business. IZA is an independent nonprofit organization supported by Deutsche Post Foundation. The center is associated with the University of Bonn and offers a stimulating research environment through its international network, workshops and conferences, data service, project support, research visits and doctoral program. IZA engages in (i) original and internationally competitive research in all fields of labor economics, (ii) development of policy concepts, and (iii) dissemination of research results and concepts to the interested public.
\end{abstract}

IZA Discussion Papers often represent preliminary work and are circulated to encourage discussion. Citation of such a paper should account for its provisional character. A revised version may be available directly from the author. 


\section{ABSTRACT}

\section{Electrification and Educational Outcomes in Rural Peru*}

We study the effects of electrification on educational outcomes in Peru by taking advantage of a program that rapidly increased electricity coverage in rural areas. Using household survey panel data from 2007-2010, we document that: i) girls living in treated districts are more likely to be enrolled in school, and this effect is larger among younger girls; ii) this positive effect on female enrollment does not translate into higher attendance rates; iii) households in treated areas spend more money on younger girls' education. In addition, we use school-level panel data from 2007-2012 on Math and Reading test scores to show that treatment is associated with a reduction in learning. But, among treated schools, longer treatment exposure increases scores in Reading for boys and girls; and improves performance in Math, only among boys. Finally, our estimates are robust to controlling for other confounding interventions.

JEL Classification: $\quad$ 125, O13, O15

Keywords: education, rural electrification, Peru

Corresponding author:

Hugo Ñopo

Inter-American Development Bank

1300 New York Avenue NW

20577 Washington, DC

USA

E-mail: hugon@iadb.org

\footnotetext{
* We are grateful to Jorge Aguero, Julian Cristia and Veronica Frisancho for very useful suggestions on previous drafts. Also, we thank participants at the 1st Annual Congress of the Peruvian Economic Association (Universidad de Piura, August 2014), and the 19th Annual Meeting of LACEA (Universidade de São Paulo, November 2014) for helpful comments. Finally, we thank the DIGETE at the Ministry of Education for kindly providing us with the data on OLPC. The views expressed herein are those of the authors and do not reflect the views of IFPRI nor the Inter-American Development Bank.
} 


\section{Introduction}

Infrastructure projects have regained attention among policy makers as they can be used to foster economic development in rural areas. This renewed interest has translated into a recent increase of empirical studies that analyze the effects of different infrastructure interventions on development indicators (see Banerjee et al. 2013 for roads construction in China; Aker 2010 for telecommunications in Niger; and Estache 2010 for a recent review on impact evaluations of infrastructure projects).

In this paper, we examine the effects of rural electrification on educational outcomes in Peru. The Peruvian case is relevant for two reasons. On the one hand, student learning in Peru remains at dismal levels despite fast macroeconomic growth and improvements in social indicators (e.g. poverty reduction). Low learning levels are reflected, for instance, on international assessments in which Peru ranks among the worst performing countries in numeracy and literacy (e.g. PISA 2009, 2012). On the other hand, in 2006 less than 40 percent of rural households had access to electricity. However, by 2012 electricity coverage was almost 70 percent due to the fast expansion of an electrification program known as PER - Programa de Electrificación Rural. As many other developing countries face similar challenges in both education and electricity coverage, our study can provide some light on how these two variables are related to each other.

Access to electricity can affect educational outcomes through different channels. In fact, we should distinguish between: i) access at home, and ii) access at school. Children who have electric light at home are benefited with better illumination during the night, and have the possibility to use electronic devices such as computers that may facilitate learning. Electricity, however, can also reduce time devoted to studying if, for instance, it increases the demand for leisure (e.g. kids start watching TV). Access to electricity at school can impact learning through better learning environments (e.g. amenities, information and learning technologies) which may be useful to both students and teachers.

Our findings can be summarized as follows. Using household panel data, we find that access to electricity has no effect on boys' educational outcomes. However, treatment increases female school enrollment, as well as the amount of money spent on girls' education. Additionally, using school panel data on Math and Reading national standardized tests, we show that treated schools have lower test scores than non-treated schools. But, among treated schools, longer treatment exposure increases scores in Reading for boys and girls; and improves performance in Math, only among boys. Our results are robust to controlling for other two interventions (a conditional cash transfers program 
and "One Laptop Per Child") that took place in rural districts during the study period.

The rest of the paper proceeds as follows. Section 2 reviews the related literature. Section 3 describes the rural electrification program. Section 4 details our data sets. Section 5 outlines the empirical strategy. Section 6 presents main results and robustness checks. Section 7 offers concluding remarks.

\section{Related Literature}

The literature on the impacts of school interventions on educational outcomes has been recently reviewed by Kremer and Holla (2009), and Glewwe et al. (2011). The former focus on randomized evaluations in developing countries while the latter review studies with both experimental and non-experimental designs. Since we are not aware of interventions that have randomized access to electricity, we follow the latter and briefly summarize four studies related to our paper, but not covered in such reviews.

From 1990 to 2010, 6 out of 79 reviewed studies in Glewwe et al. (2011) provide estimates for the effects of electrification on test scores. Based on the empirical methods of each study, the authors divide their 79 papers into: i) 36 regular studies (3 on electrification), and ii) 43 high-quality studies (3 on electrification). Among the 3 regular studies, the estimated coefficients on electricity access are mostly positive and significant (3 coefficients are positive but insignificant, and 6 are positive and significant). Among the 3 high-quality studies, only insignificant (3 negative and 3 positive) effects are found ${ }^{1}$. These reviewed studies, however, are not especially interested in estimating the educational impacts of access to electricity but rather include this variable on their regressions along with other control variables.

Aside from these studies on school interventions, there are four recent empirical papers not included in the previous reviews, closely related to ours. Khandker et al. (2009) use household panel data from rural Vietnam and compare households with and without electricity connection to show that electrification has positive and significant effects on household income and expenditures, and school enrollment. They also find that these benefits level off after 9 years of electricity use.

Dinkelman (2011) is the first paper using a clean identification strategy to quantify the consequences of electrification on labor outcomes in rural South Africa. Using land gradient as an instrument for electrification, and

\footnotetext{
${ }^{1}$ There are more estimates than studies because some papers provide more than one estimated effect (e.g. rural versus urban).
} 
complementing her IV estimates with fixed-effect models, her results indicate that female employment increases in treated areas. In a similar spirit, Rud (2012) studies the effects of electrification on industrial production in India, using river water flow as an instrument for access to electricity.

Finally, Libscomb et al. (2013) use county-level data from urban and rural Brazil to examine the impacts of electrification on the Human Development Index (HDI). Their strategy consists of simulating electricity grid expansion taking only into account topographic considerations (water flow and river gradient). Then, the authors use these predictions as instrumental variables for actual program placement. They document large positive effects on the income and education (literacy and enrollment rates) components of the index but not on health (life expectancy). These large estimated effects, however, may be driven by the fact that the IV approach uses variation on compliers which, by construction, are counties with the most cost-effective electrification projects.

Our work adds to this recent and growing literature in two ways. First, we pay attention to household responses (expenditures on child's education) which are crucial to correctly interpret the estimates of electrification on educational outcomes. Second, we provide evidence on the effects of electrification on test scores which are a better proxy for human capital given the low levels of school quality in developing countries in spite of increasing enrollment rates (Hanushek and Woessmann 2008).

\section{The Rural Electrification Program}

In 1993, 60 percent of rural households were poor and only 7 percent had access to electricity. At that time, the Ministry of Energy and Mining launched an electrification program named PER - Programa de Electrificación Ruralin order to improve this situation and promote social and economic development in rural areas. Electrification projects were not randomly assigned across districts. Instead, they gave priority to districts with:

- lower electricity coverage (percentage of households with electricity)

- higher poverty rate (percentage of households whose consumption is below the national poverty line)

- lower proportion of the estimated subsidy per connection

- lower cost per connection

- higher use of renewable energy 
The Ministry defined the roll-out of the program using these variables. In Figure 1, we present graphical evidence of the rapid increase in electricity coverage. In particular, we compare access to electricity at home across treated and non-treated districts. As expected by the priority criteria, at the beginning of the study period, PER districts had an electricity coverage 10 percentage points lower than non-PER districts. Four years after, the gap had been reversed and treated districts had higher coverage than control districts. This figure shows that access to electricity in PER districts increased by 20 percentage points in only four years. The program's goal is to increase electricity coverage up to 90 percent in all rural areas before 2023.

In this paper, we focus on projects that were concluded in the period 2007-2010 for three reasons. First, 90 percent of projects concluded before 2013 were finished between 2007-2010. Second, the National Office of Statistics (INEI for its name in Spanish) collected a unique household panel data set from 2007 to 2010. Third, the Ministry of Education also administered national standardized tests to all 2nd-graders in the country during 20072012.

From 1994 to 2012, 628 electrification projects were concluded throughout rural Peru (554 were finished between 2007-2010) with a total cost of US\$ 657.5 million. Figure 2 depicts program expansion by year. We see that, for each year, PER implementation is not concentrated in any single geographical area. Rather, program expansion seems to be evenly distributed across districts.

\section{Data}

We use three data sources in our empirical analysis: i) household-level panel data; ii) school-level panel data; and iii) administrative data on electrification projects. Further details of each data set are provided below.

First, we use a household panel data set known as ENAHO - Encuesta Nacional de Hogares- conducted by INEI between 2007-2010. This survey includes comprehensive information (education, health, employment, and so on) at both the household and individual level. ENAHO is representative at the national, urban and rural level but we confine our analysis to rural districts because urban areas were not targeted by PER.

For each individual between ages 3 and 18 in 2007, we construct three outcomes: i) enrollment; ii) attendance; iii) log of household education-related expenditures per child ${ }^{2}$. Both enrollment and attendance are discrete vari-

\footnotetext{
${ }^{2}$ In practice, we add 1 to each amount of expenditures (expressed in Nuevos Soles) because $20 \%$ of the observations have zero expenditures. Therefore, our dependent variable
} 
ables, and the latter is constructed only for individuals enrolled in school (attendance conditional on enrollment). Educational expenditures per child include: uniform and shoes, textbooks, materials, fees, and parent's associations.

Second, we use six rounds of the national standardized test, named ECE - Evaluación Censal de Estudiantes-, administered by the Ministry of Education, and taken by all 2nd-graders in Peru between 2007-2012. At the end of each school year (early December), students are evaluated in Math and Reading skills, using a three-level scale grading system (from highest to lowest): proficient, partially proficient, and not proficient. For each school, year and subject, we calculate two outcomes: the percentage of students who reached the highest proficiency level of the exam; and the percentage of students in the lowest level. To ensure that these school-level outcomes are meaningful, we restrict our sample to schools with at least 5 students in both 2007 and 2008, and also weight all regressions by the number of test takers in each school at baseline (year 2007). Furthermore, we restrict our sample to schools that took the test every year.

Third, we use administrative records of the Ministry of Energy and Mining which contain the list of electrification projects that were concluded between 2007 and 2010. In our study period, 554 projects - out of 628 since 1994- were concluded in 412 rural districts. For each project, we observe the year of conclusion, and the treated districts (101 projects include more than one district).

For the household-level analysis, we match ENAHO and PER data sets using district identifiers, ENAHO survey year, and year of conclusion of each project. For the school-level analysis, we match ECE and PER data sets using district identifiers, exam year, and project's year of conclusion. After doing so, our ENAHO-PER and ECE-PER samples include 2,400 individuals, and 4,539 schools, respectively.

Table 1 presents descriptive statistics of control and treatment groups in the year 2007 for both panel data sets. In control districts, around 80 percent of households have a male head and 85 percent in treated districts but this difference is not statistically significant. Household heads are between 48 and 50 years old in the sample, and this small difference between groups is only significant at the 10 percent level. In control areas, 11 percent of household heads do not have formal education while in treated areas this figure goes up 14 percent, however, this difference is not statistically significant. In both groups, around half of the household heads speak an indigenous language,

is $\log$ (expenditures+1). The average expenditure before and after such modification is 101 and 102 Nuevos Soles, respectively. 
different from Spanish. Also, heads in both groups have a monthly income between 240 and 260 Nuevos Soles, which is equivalent to 80 and 90 US current dollars.

In the school data set, we see that schools in control districts have more students than in treated areas, though this difference is very small in magnitude (less than one student). Finally, the proportion of male students is 51 percent in both groups. Overall, both groups look similar along these characteristics. Most differences are statistically insignificant, and when they are significant (only two variables) they are very small.

\section{$5 \quad$ Empirical Strategy}

Cross-sectional comparisons between households with and without electricity are likely to deliver inconsistent estimates of the effects of electrification because these households may differ in other (unobserved) dimensions. We avoid such comparisons by taking advantage of the rapid increase in electricity coverage due to PER expansion, and using individual and school panel data to control for unobserved characteristics that may determine both PER placement and outcomes. In particular, we adopt a Fixed-Effects (FE) approach to estimate the impact of PER on educational outcomes by using within-individual (and within-school) variation over time in access to electricity.

For simplicity, we only refer to individuals throughout this section though we later use both individual-level and school-level panel data. To fix ideas, let $i=1,2, \ldots, N, j=1,2, \ldots M$, and $t=1,2, \ldots, T$ denote, individuals, districts and years, respectively. This setup lead us to estimate the following equation:

$$
y_{i j t}=\alpha_{i}+\alpha_{j}+\alpha_{t}+\beta P E R_{j t}+\mu_{i j t}
$$

where $y_{i j t}$ is the outcome variable (e.g., enrollment, attendance) of individual $i$ living in district $j$ at period $t$. Unobserved individual heterogeneity is captured by $\alpha_{i}$. Time-invariant district characteristics (geographic characteristics that may determine PER placement) and year-specific effects are denoted by $\alpha_{j}$ and $\alpha_{t}$, respectively. $P E R_{j t}$ indicates that, in district $j$, at least one electrification project has been concluded by year $t$. The error term is denoted by $\mu_{i j t}$ and is clustered at the individual level.

The inclusion of individual fixed effects has two consequences. The first one is that we cannot include characteristics that are time-invariant (sex, maternal language, birth weight) because they are already captured by $\alpha_{i}{ }^{3}$.

\footnotetext{
${ }^{3}$ We distinguish the individual fixed effect from the district fixed effect only to be as
} 
The second consequence is that the effect of PER on educational outcomes is estimated using within-individual variation over time. In fact, the key assumption to apply a FE strategy is that unobserved confounders are timeinvariant.

The first question we seek to answer with our analysis is whether PER has an impact on educational outcomes, after controlling for individual heterogeneity, and a set of fixed effects. Thus, in equation (1), $\beta$ is the parameter of interest. As noted by Duflo et al. (2006), this coefficient should be interpreted as the overall effect (total derivative) of providing electricity at the district level rather than seeing it as the effect of having electricity, holding everything constant (partial derivative). In this sense, $\beta$ is not a structural parameter, but it is informative to policy makers because it tells us the difference in outcomes between individuals who are exposed to PER and those who are not.

A second related question is whether individuals who live in districts that receive more electrification projects experience larger effects. In our sample, around one third of treated districts received more than one electrification project between 2007-2010. These differences in treatment "intensity" among treated districts allow us to estimate a second equation:

$$
y_{i j t}=\gamma_{i}+\gamma_{j}+\gamma_{t}+\phi I N T E N S I T Y_{j t}+\nu_{i j t}
$$

where INTENSITY $Y_{j t}$ is measured as the cumulative number of concluded projects in district $j$ by year $t^{4}$. For instance, if a district receives one project per year, from 2007 to 2010, its intensity measure would be as follows: 1,2,3,4. Therefore, $\phi$ represents the marginal impact of concluding one additional project, conditional on being exposed to the program. All other variables are defined as in equation (1). The identifying assumption of equation (2) is that our measure of intensity is uncorrelated with the error term once we control for individual, district and year fixed effects.

A third question is whether individuals exposed for longer periods to electricity experience larger effects. To test whether this is the case, we construct a measure of temporal exposure to PER and estimate a third equation:

$$
y_{i j t}=\lambda_{i}+\lambda_{j}+\lambda_{t}+\rho E X P O S U R E_{i j t}+\varepsilon_{i j t}
$$

clear as possible. However, in practice, they are not distinguishable because individuals in our panel do not migrate. Therefore, the district of residence is captured in the individual fixed effect.

${ }^{4}$ In other words, our measure of intensity is not the number of projects concluded each year. Instead, is the cumulative number of projects concluded by year (i.e. it is increasing over time). 
where EXPOSURE $E_{i j t}$ indicates the number of months between the project's year of conclusion and the month of the individual's interview. For instance, if one project was concluded in 2007, and an individual was surveyed in September 2008, then we would say that this individual had been exposed to PER for 9 months $^{5}$. The effect of one additional month of exposure to PER is denoted by $\rho$. This coefficient is useful to check whether individuals with longer periods of exposure to PER experience larger impacts.

This set of equations and their corresponding parameters constitute the basis of empirical analysis. For each equation, we explore various educational outcomes (e.g., enrollment, test scores) and use different data sets (household and school-level panel data).

Before discussing our main results, we briefly analyze the effects of PER, intensity and exposure on actual access to electricity at home. To do so, we use the ENAHO household panel sample and separately regress an indicator variable for access to electricity on PER, intensity and exposure using household fixed-effect models ${ }^{6}$. Table A1 in the Appendix shows the point estimates of each regression. As we can see, our independent variables of interest are strongly and positively correlated with access to electricity. These results suggest that the program actually leads to higher electricity coverage among treated households.

\section{Results}

\subsection{Enrollment, Attendance and Expenditures}

We begin by presenting the estimated effects of PER on enrollment, attendance and educational expenditures using ENAHO panel data. As an attempt to explore if there are gender differences, we group our results in three samples: the whole sample, only boys and only girls. Furthermore, for each outcome variable, we split each sample in four sub-samples using individuals' age in 2007: 1) all ages; 2) between 3 and 5 (pre-primary level); 3) between 6 and 12 (primary level); and 4) between 13 and 18 (secondary level).

Table 2 shows our results using the whole sample. For each age group, we present the coefficients on PER, INTENSITY, and EXPOSURE in Panel A, B and C, respectively. Consistent with previous studies (see Glewwe et al. 2012), the point estimates in Panel A suggest that living in a PER

\footnotetext{
${ }^{5}$ If there were two (or more) projects in a given district, we use the date of the project that concluded first.

${ }^{6}$ The ENAHO household panel sample is simply the individual panel data set we use in our analysis but collapsed at the household level.
} 
district does not affect enrollment (columns 1-4); attendance (columns 5-8); and log of educational expenditures (columns 9-12), except for the negative impact on educational expenditures on the oldest children (column 12). In Panel B, we see that, conditional on being treated, each additional electrification project increases enrollment by around 3 percentage points among the youngest individuals (column 2). Panel $\mathrm{C}$ shows that temporal exposure to PER does not affect enrollment nor attendance. However, it has small but negative effects on educational expenditures among children aged 6-12 (column 11), and positive impacts among older children (column 12).

We present analogous estimates for the male sample in Table 3. Point estimates in Panel A suggest that treatment does not affect educational outcomes. Figures in Panel B suggest that, conditional on having received PER, concluding an additional electrification project has small negative effects on male enrollment (column 1) but does not affect attendance nor expenditures. Coefficients in Panel $\mathrm{C}$ are small and statistically insignificant, suggesting that temporal exposure to PER does not have an impact on educational outcomes.

Table 4 presents results for the female sample. In Panel A, we find that PER increases enrollment by around 3.5 percentage points among girls of all ages (column 1), and the effect is larger among younger girls (column 2). In spite of these positive impacts on enrollment, coefficients in columns 5-8 indicate that PER has no significant effects on attendance. These results may indicate that electrification leads to higher demand for schooling (enrollment) but then these girls actually fail to attend to school because other constraints may still exist. We also find that treatment increases expenditures on girls aged 6 to 12 (column 11) by 20 percent, but decreases expenditures on older girls (column 12) by around 35 percent. In Panel B, we see that, conditional on being treated, each additional electrification project increases enrollment by 2 percentage points among girls (column 1 ) but attendance remains unaffected. In the last four columns, we show that educational expenditures are significantly higher in districts that received more electrification projects. In Panel C, we find that, conditional on being treated, temporal exposure to the program has negative but very small effects on attendance among girls aged 6-12 (column 7), and positive impacts on educational expenditures on the oldest girls (column 12).

Taken together, our results using ENAHO panel data suggest that girls -especially the youngest - are benefited from the program. Recall that these estimates should be interpreted as the overall effect of providing electricity (total derivative) rather than as the effect of electrification holding everything else constant (partial derivative). As shown in other contexts (Das et al. 2013), this distinction matters for policy discussions or external valid- 
ity concerns because treatment can affect educational outcomes directly but could also have indirect effects (households or communities may respond to the treatment and affect outcomes through other channels). For instance, Dasso and Fernandez (2013) using the ENAHO panel data show that PER increases female adults' earnings which, in turn, may increase school enrollment and education-related expenditures.

From a policy perspective, one may suspect that higher enrollment rates could also raise grade repetition rates. However, when we examine the effects of the program (as well as treatment intensity and temporal exposure) on this outcome, we find no evidence to support this view (results not shown but are available from the authors upon request).

\subsection{Math and Reading Test Scores}

We turn to discuss whether the program increases school learning as measure by the fraction of students who meet the proficiency standard in the national test. Note that the interpretation of the following estimates is not the same as in the previous section. In what follows, the treatment consists of receiving electricity in the school (i.e. an increase in school inputs) while in the previous section the treatment was receiving electricity in the district of residence (i.e., an increase in household inputs).

Table 5 shows the effects of PER on learning for the whole sample. In Panel A, the estimates of columns 1 and 2 indicate that schools located in PER districts do not generate higher learning in Math than schools located in non-treated districts. In columns 3 and 4, we see that PER has a negative effect on reading skills: it increases the percentage of students who are not proficient (lowest level) and reduces the percentage of students that are proficient (highest level). However, in Panel C, proficiency rates go up by 0.1 percentage points per month of exposure (column 4). This last result may indicate that the learning benefits of electrification do not immediately materialize.

We present analogous estimates only for male students in Table 6. Again, we do not see any action on Math proficiency rates (see columns 1 and 2) since the coefficients are small and statistically insignificant. In contrast, the point estimates of column 4 suggest that receiving PER decreases learning in Reading though this decline fades out as exposure to the program increases (Panel C). Given that these two effects go in opposite directions, they could compensate each other in the long run.

Results including only female students are shown in Table 7. As in the case of boys, PER does not seem to have any impact on Math learning rates. In Reading, however, treatment decreases learning rates (Panel A, columns 
3 and 4) but temporal exposure to PER increases it (Panel C, column 4). This last coefficient implies that, after 14 months of treatment exposure, proficiency rates in Reading go up by 1 percentage points.

Overall, our results suggest that schools with access to electricity do not experience learning gains in Math. This finding is consistent with previous studies on the impact of school resources and test scores which generally show insignificant estimates. In Reading, we find that schools in treated district obtain lower scores than schools in non-treated areas. Interestingly, this negative impact is compensated with learning gains as treatment exposure increases. In the long run, the final effect of electrification on Reading test scores may be positive if the effect of temporal exposure is monotonic and persistent.

\subsection{Robustness Checks}

\subsubsection{Pre-treatment differences in educational outcomes}

Even after controlling for unobservable time-invariant characteristics, and showing that covariates were balanced across treated and control districts, our estimates could still be capturing pre-treatment differences in our outcome variables. More specifically, program placement could be correlated with prevailing time-varying differences in enrollment, attendance or expenditures, and these differences would, in turn, mechanically translate into post-program differences.

To rule out this possibility, we need data on outcomes from pre-intervention years. However, both ENAHO panel data and ECE school-level data are only available from 2007 onward. Given this limitation, we use ENAHO annual cross-sections for the period 2004-2006. ENAHO cross-sections and panel data are very similar except for the fact that the former does not follow individuals over time: it draws a new sample each year.

To formally test whether program placement between 2007-2010 is correlated with pre-intervention outcomes, we regress each outcome variable on a future treatment indicator for each pre-intervention year ${ }^{7}$. Finding significant differences between districts that have not been treated yet, should raise concerns on the validity of our empirical strategy. Table A2 (see the Appendix) presents point estimates from each regression. In all cases, we find small differences -smaller than 0.05 in absolute terms- and all of them are statistically insignificant. This evidence is reassuring because it suggests that pre-treatment time-varying differences are not driving our results.

\footnotetext{
${ }^{7}$ We construct all outcome variables following the same procedure mentioned in Section 4.
} 


\subsubsection{Controlling for other interventions}

During our study period (2007-2010) there were two main programs that also arrived to some rural districts from our sample, and could have affected educational outcomes.

First, the Peruvian conditional cash transfer (CCT) program, named "Juntos", rapidly reached more than 600 rural districts between 2005 to 2010. As is usual in these programs, the female head of the household receives a monthly stipend conditional on sending her children to school and taking them to health centers on a regular basis. To the extent that the presence of Juntos could increase school enrollment, attendance (through its conditions) and educational expenditures (through its cash payments), it is crucial to rule out that our results are not driven by Juntos' conditions nor its cash benefits even though PER and Juntos were rolled-out independently and without any coordination ${ }^{8}$.

Second, the Ministry of Education launched the "One Laptop per Child (OLPC)" program in 2008, and within this year, it delivered around 40,000 laptops to children from 500 primary schools in rural areas. Each laptop costs around $\$ 200$ so this intervention was relatively costly. As of today, the Peruvian case is one of the largest deployments in the world made by the "One Laptop per Child" initiative (Cristia et al 2012). OLPC targeted around 1,900 small primary schools, located in the poorest regions of Peru. Its implementation had two waves. In the first one, districts with both access to electricity and internet connection were prioritized. In the second wave, the former requirement was kept but the latter was abandoned because most poor districts lacked internet access. Therefore, OLPC implementation was, by construction, correlated with PER placement even though both programs were run independently.

The presence of these two interventions in PER districts could introduce bias in our main estimates. To address these concerns, we redo the analysis but now controlling for the presence of Juntos and OLPC. Administrative data from Juntos roll-out from 2005 to 2011 was provided by Juntos officials upon request from the authors. These data indicates the year when the program arrived at a given district. Administrative data from OLPC rollout (including both waves) was provided by the General Office of Technology for Education, at the Ministry of Education. These data indicates the year when OLPC arrived at a given school.

We match these two data sets on programs' roll-outs with ENAHO and

\footnotetext{
${ }^{8}$ During 2005-2012, Juntos was affiliated to the Office of the Council of Ministers. The program pursued different objectives from PER and used different criteria for its roll-out (e.g., children chronic malnutrition, exposure to violence during the 1980's armed conflict).
} 
ECE data sets. In the empirical analysis using ENAHO data, we control for the presence of these programs at the district level. That is, we include a dummy for each program that is equal to 1 if the program is in the district and 0 otherwise. In the analysis using ECE data, we also control for Juntos at the district level, but we are able to control for OLPC at the school level. That is, we include a dummy equal to 1 if Juntos is in the district and 0 otherwise, and a dummy that takes the value of 1 when the school is treated by OLPC and 0 otherwise.

Table 8 present results of the effects of PER on educational outcomes using ENAHO for the whole sample. Point estimates are very similar to those in Table 2. The fact that results remain unchanged after controlling for both programs suggest that these interventions are not biasing our main estimates. In Tables A3 and A4 in the Appendix, we report the point estimates for the boys' and girls' samples and, again, we find no differences with respect to Tables 3 and 4 , respectively.

We show the estimated effects of electrification on test scores using ECE data, after controlling for Juntos and OLPC in Table 9. These results are again similar to those in Table 5, which indicates that these programs are not driving our estimates. Tables A5 and A6 in the Appendix present the corresponding estimates for the boys' and girls' samples. In these samples, we also find that the inclusion of these programs does not affect our main estimates.

Therefore, our main results are robust to the inclusion of two main interventions that could affect educational outcomes in rural districts. The stability of our estimates is in line with previous studies that have separately estimated the effects of Juntos on enrollment and attendance (Perova and Vakis 2012), and the effects of OLPC on tests scores (Cristia et al. 2012) and have found little evidence of positive impacts.

\section{Concluding Remarks}

Improving student learning and providing access to services such as electricity are policy priorities in developing countries. At the same time, there is an open academic debate on whether school resources are relevant for learning. This study aims to provide new evidence on this issue by analyzing the impact of electrification on educational outcomes in Peru.

To do so, we take advantage of an unusually rapid expansion of an electrification program that increased electricity access in rural Peru. Between 2007-2010, 554 electrification projects reached several rural districts of the country leading to substantial improvements in electricity coverage in only a 
few years.

Using household survey panel data from 2007-2010, we document the following results. Among boys, the electrification program does not affect school enrollment, attendance nor education-related expenditures. Among girls, we find that female enrollment rates are higher in treated districts than in non-treated areas though this positive effect on enrollment does not lead to higher attendance rates. We also find that treated households spend more on young girls' education. Moreover, the effects on female school enrollment and educational expenditures are larger in areas that received more electrification projects.

Then, we use school-level panel data on Math and Reading test scores administered by the Ministry of Education between 2007-2012. The electrification program is associated with a decrease in student learning although, among treated schools, longer treatment exposure improves scores in Reading for boys and girls; and increases Math performance, only among boys. If such positive effects are persistent and do not decline over time, electricity provision can slowly produce gains in learning over the long run.

From a policy perspective, efforts to increase access to electricity should not abandoned. Other pieces of evidence indicate that electrification improves other economic outcomes (e.g. employment) that could indirectly increase educational outcomes. 


\section{References}

[1] Aker, J. (2010): "Information from Market Near and Far: The Impact of Mobile Phones on Grain Markets in Niger"; American Economic Journal: Applied Economics, N. 2 , July 2010, pp. 46-59

[2] Angrist, J. and Pischke, J. S. (2009): "Mostly Harmless Econometrics, An Empiricist's Companion"; Princeton University Press, 2009

[3] Baneruee, A.; Duflo, E. and Quian, N. (2012): "On the Road: Access to Transportation Infrastructure and Economic Growth in China"; National Bureau of Economic Research, Working Paper N. 17897, March 2012

[4] Bedi, A. and Marshall, J. H. (1999): "School attendance and student achievement: Evidence from rural Honduras"; Economic Development and Cultural Change, 47 (3) (Apr.), pp. 657-682

[5] Beurmann, D. (2011): "Telecommunication Technologies, Agricultural Profitability and Child Labor in Rural Peru"; Central Bank of Peru, Working Paper Series, 2011-02

[6] Beurmann, D; McKelvey, C. and Sotelo, C. (2012): "The Effects of Mobile Phone Infrastructure: Evidence from Rural Peru"; Central Bank of Peru, Working Paper Series, 2012-12.

[7] Cristia, J.; Ibarraran, P.; Cueto, S.; Santiago, A. and SevERIN, E. (2012): "Technology and Child Development: Evidence from the One Laptop Per Child Program"; Inter-American Development Bank Working Paper N. 304, Washington DC, February 2012

[8] Dasso, R. and Fernandez, F. (2013): "The Effects of Electrification on Employment in Rural Peru"; CEDLAS Working Paper N. 150, October 2013

[9] Dinkelman, T. (2011): "The Effects of Rural Electrification on Employment: Evidence from South Africa"; American Economic Review, N. 101, December 2011, pp. 3078-3108

[10] Das, J.; Dercon, S.; Habyarimana, J.; Krishnan, P.; MuralidHaran, K. and Sundararam, V. (2013): "School Inputs, Household Substitution, and Test Scores"; American Economic Journal: Applied Economics, N. 5, April 2013, pp. 29-75 
[11] Duflo, E.; Glennerster, R. and Kremer, M. (2006): "Using Randomization in Development Economics Research: A Toolkit"; National Bureau of Economic Research, Technical Working Paper 333, December 2006

[12] Escobal, J. (2005): "The Role of Public Infrastructure in Market Development in Rural Peru"; PhD Thesis, Wageningen University, The Netherlands, 2005

[13] Estache, A. (2010): "A Survey of Impact Evaluations of Infrastructure Projects, Programs and Policies"; European Centre for Advanced Research in Economics (ECARES) Working Paper 2010-005, 2010

[14] Fehrler, S.; Michaelowa, K. and Wechtler, A. (2009): "The Effectiveness of Inputs in Primary Education: Insights from Recent Student Surveys for Sub-Saharan Africa"; The Journal of Development Studies, 45 (9), pp. 1545-1578

[15] Glewwe, P.; Hanushek, E. ; Humpage, S. and Ravina, R. (2011): "School Resources and Educational Outcomes in Developing Countries: A Review of the Literature from 1990 to 2010"; National Bureau of Economic Research, Working Paper N. 17554, October 2011

[16] Glewwe, P. and Jacoby, H. (1994): "Student Achievement and Schooling choice in Low-income Countries: Evidence from Ghana"; The Journal of Human Resources, 29 (3), pp. 843-864

[17] Glick, P. and Sahn, D. (2009): "Cognitive Skills among Children in Senegal: Disentangling the roles of schooling and family background"; Economics of Education Review, 28 (2), pp. 178-188

[18] Hanushek, E. and Woessmann, L. (2008): "The Role of Cognitive Skills in Economic Development"; Journal of Economic Literature,V. 46, September, pp. 607-668

[19] Imbens, G. and Wooldridge, J. (2009): "Recent Developments in the Econometrics of Program Evaluation"; Journal of Economic Literature, V. 47, March, pp. 5-86

[20] Khandker, S.; Barnes, D.; Samad, H. and Huu Minh, N. (2009): "Welfare impacts of Rural Electrification: Evidence from Vietnam"; World Bank Policy Research Working Paper N. 5057, 2009 
[21] Libscomb, M.; Mobarak, A. M. and Barham, T. (2013): "Development Effects of Electrification: Evidence from Topographic Placement of Hydropower Plants in Brazil"; American Economic Journal: Applied Economics, N. 5, April 2013, pp. 200-231

[22] Kremer, M. and Holla, A. (2009): "Improving Education in the Developing World: What Have We Learned from Randomized Evaluations?"; Annual Review of Economics, 1, pp. 513-542

[23] Lloyd, C.; Mete, C. and Grant, M (2009): "The Implications of Changing educational and family circumstances for children 's grade progression in rural Pakistan"; Economics of Education Review, 28 (1), pp. $152-160$

[24] Lloyd, C; Mensch, B. and Clark, W. (2000): "The Effects of primary school quality on school dropout among Kenyan girls and boys"; Comparative Education Review, 44 (2) (05), pp. 113-147

[25] Perova, E. and VAkis, R. (2012): "5 years in Juntos: New Evidence on the Program's Short and Long-term Impacts"; Revista Economía, Pontificia Universidad Católica del Perú , V. 35(69), pp. 53-82

[26] Rud, J. P. (2012): "Electricity provision and industrial development: Evidence from India"; Journal of Development Economics, N. 97, pp. 352-367

[27] Torero, M.; Álcazar, L. and Nakasone, E. (2007): "Provision of Public Services and Welfare of the Poor: Learning from an Incomplete Electricity Privatization Process in Rural Peru "; IDB Working Paper N. 221, August 2007 
Figure 1: Electricity coverage in rural Peru, 2007-2010

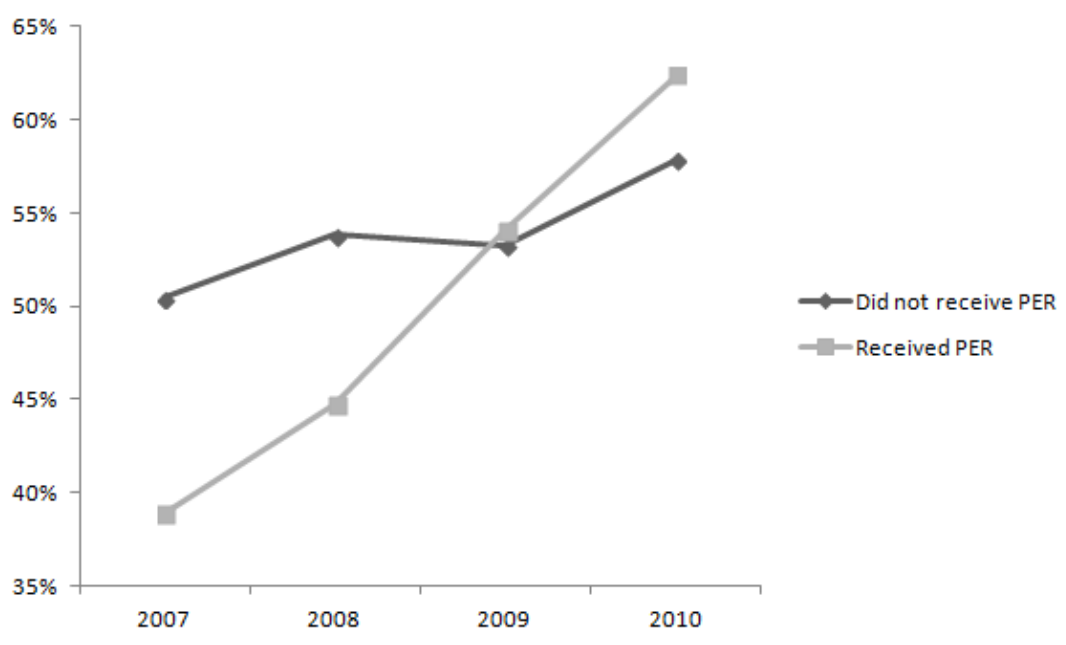

Source: ENAHO panel sample. Only includes rural areas. Coverage is measured by the percentage of households who report having access to electricity at home. 
Figure 2: Electrification projects by year of conclusion at the district level, 2007-2010

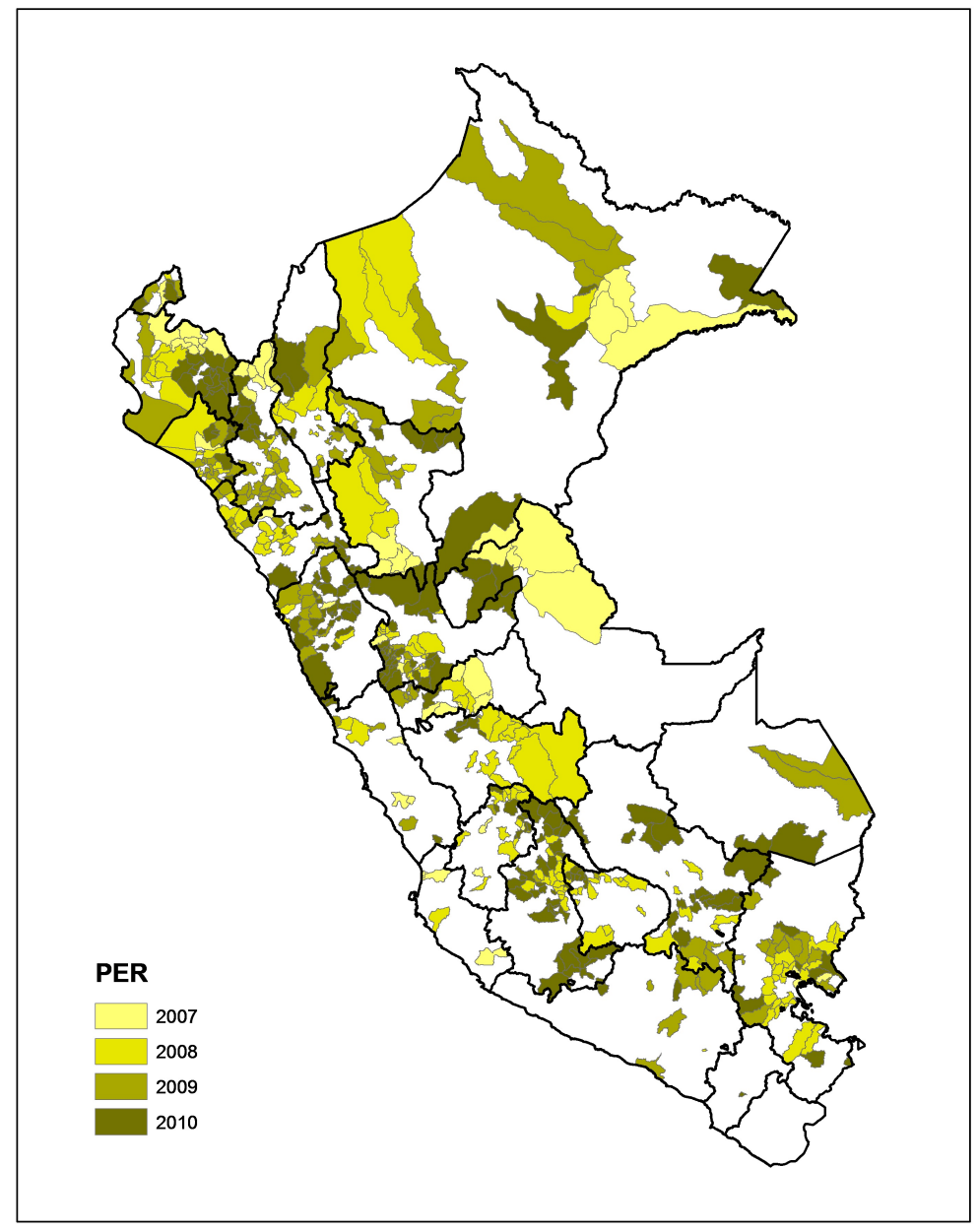


Table 1: Mean comparisons between control and treatment groups in 2007

\begin{tabular}{lccc} 
Variables in year 2007 & $\begin{array}{c}\text { Control } \\
(1)\end{array}$ & $\begin{array}{c}\text { Treatment } \\
(2)\end{array}$ & $\begin{array}{c}\text { p-value for t-test } \\
\text { on: }(1)=(2)\end{array}$ \\
\hline ENAHO panel data: & & & \\
HH head is male & 0.81 & 0.85 & 0.114 \\
& $(0.018)$ & $(0.015)$ & \\
HH head's age & 50.47 & 48.74 & 0.0784 \\
& $(0.738)$ & $(0.651)$ & \\
HH head has no formal education & 0.11 & 0.14 & 0.2774 \\
& $(0.014)$ & $(0.014)$ & \\
HH head's maternal language is Spanish & 0.54 & 0.56 & 0.5563 \\
& $(0.022)$ & $(0.020)$ & \\
HH head's monthly income & 245.50 & 227.20 & 0.4775 \\
& $(18.94)$ & $(17.31)$ & \\
& & & \\
ECE panel data: & & & \\
Number of students & 13.36 & 13.96 & 0.0184 \\
& $(0.193)$ & $(0.158)$ & \\
\% of male students & 0.518 & 0.514 & 0.4216 \\
& $(0.004)$ & $(0.003)$ & \\
\hline
\end{tabular}

NOTE: Standard errors are shown in parentheses. 


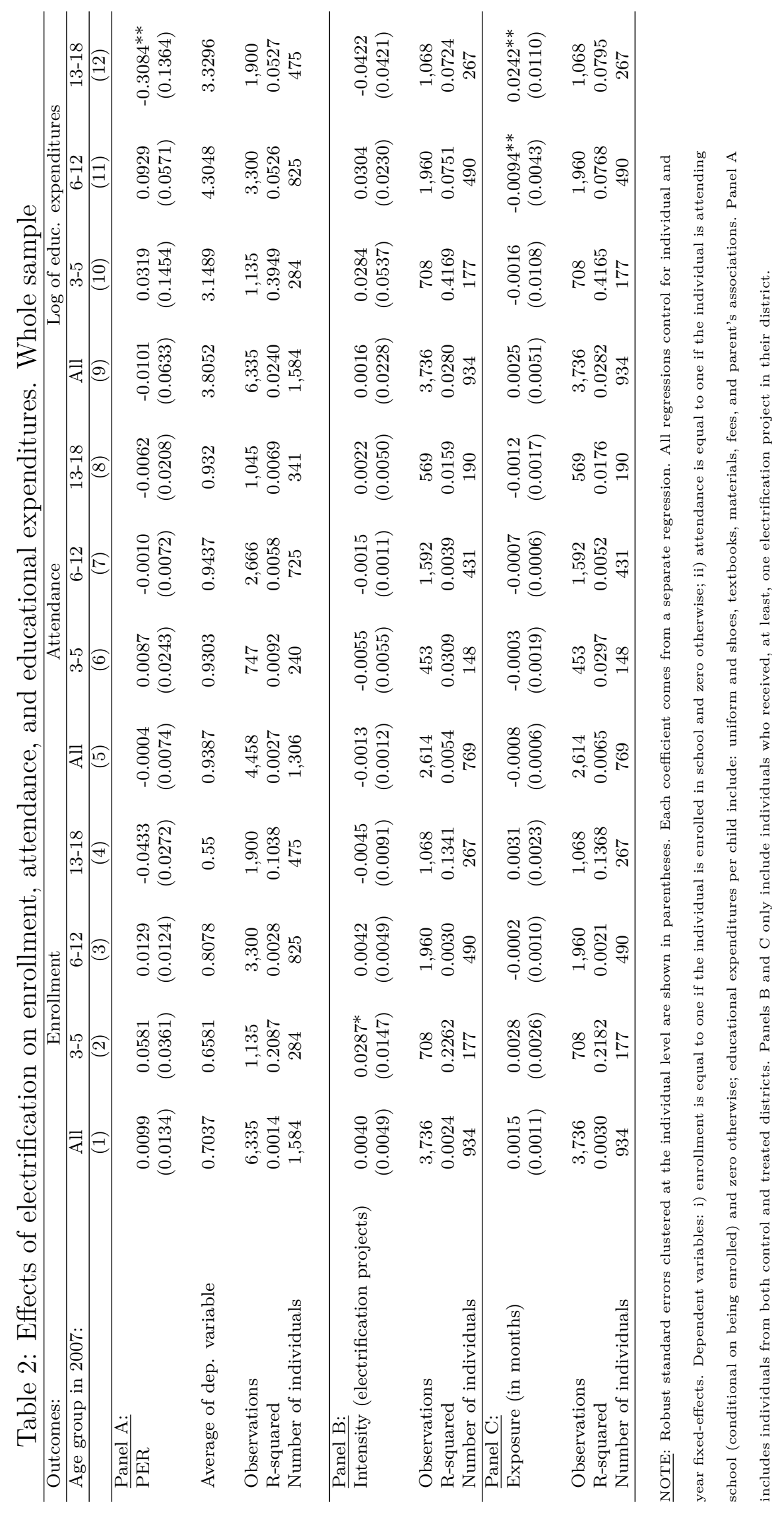




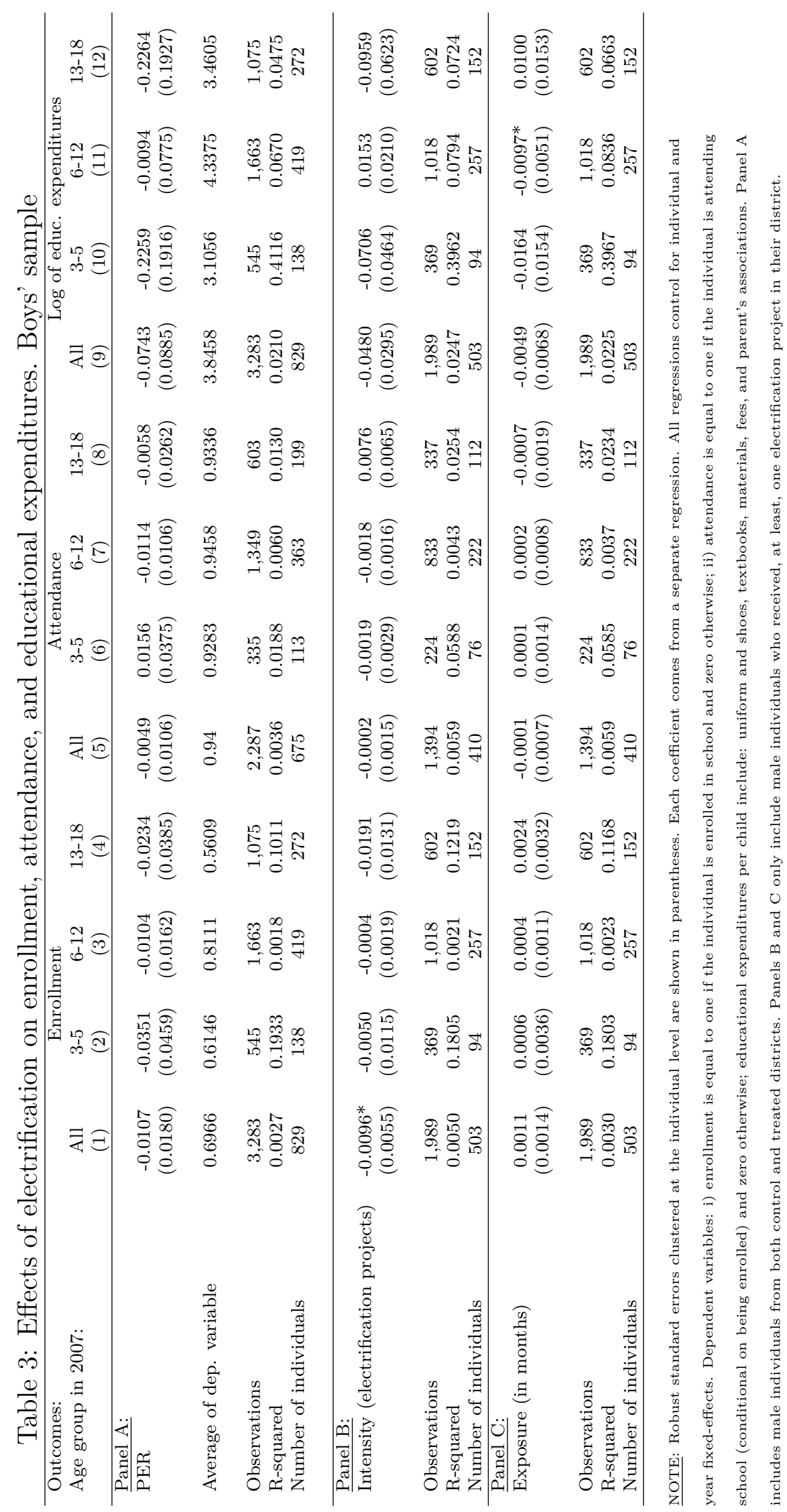




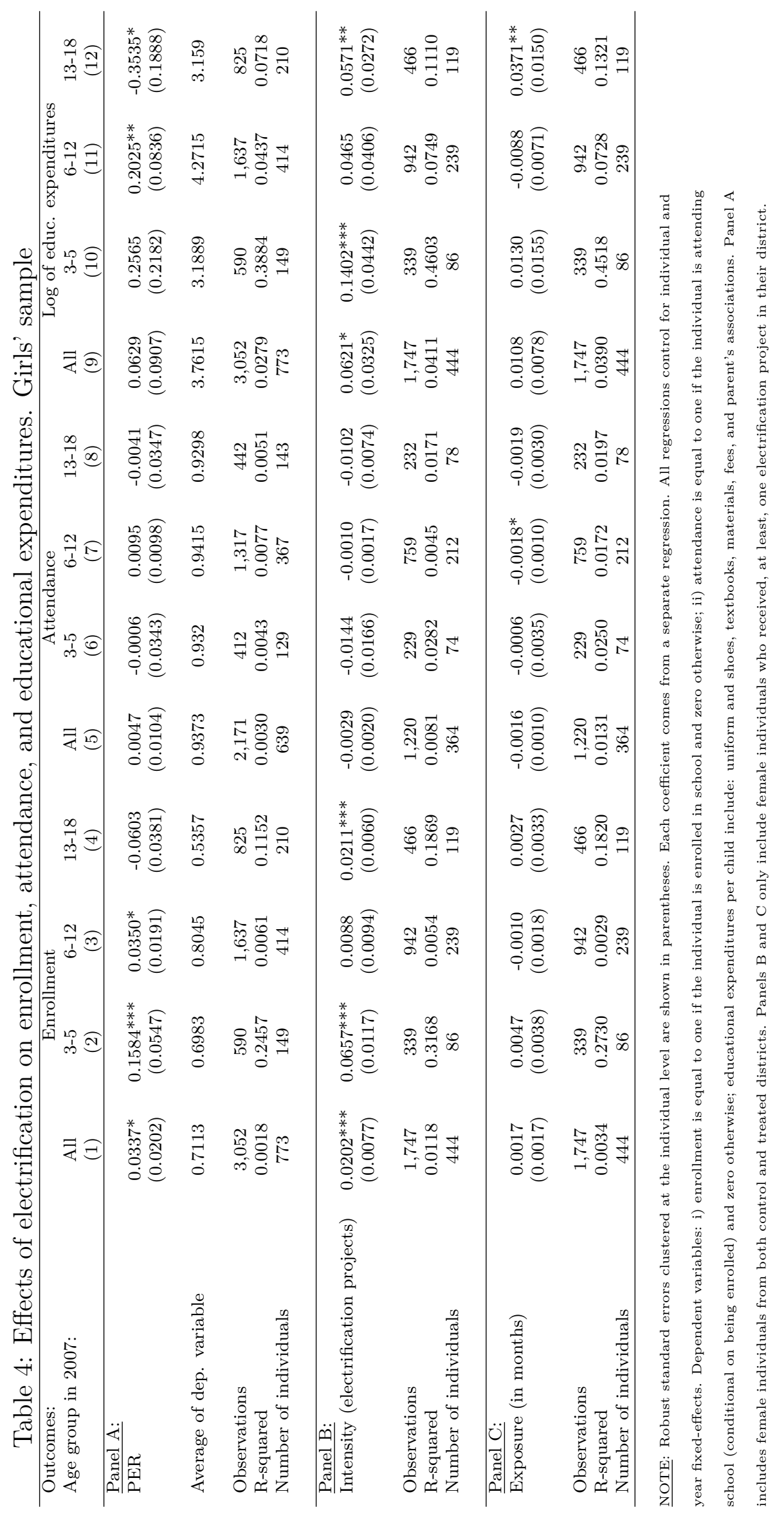




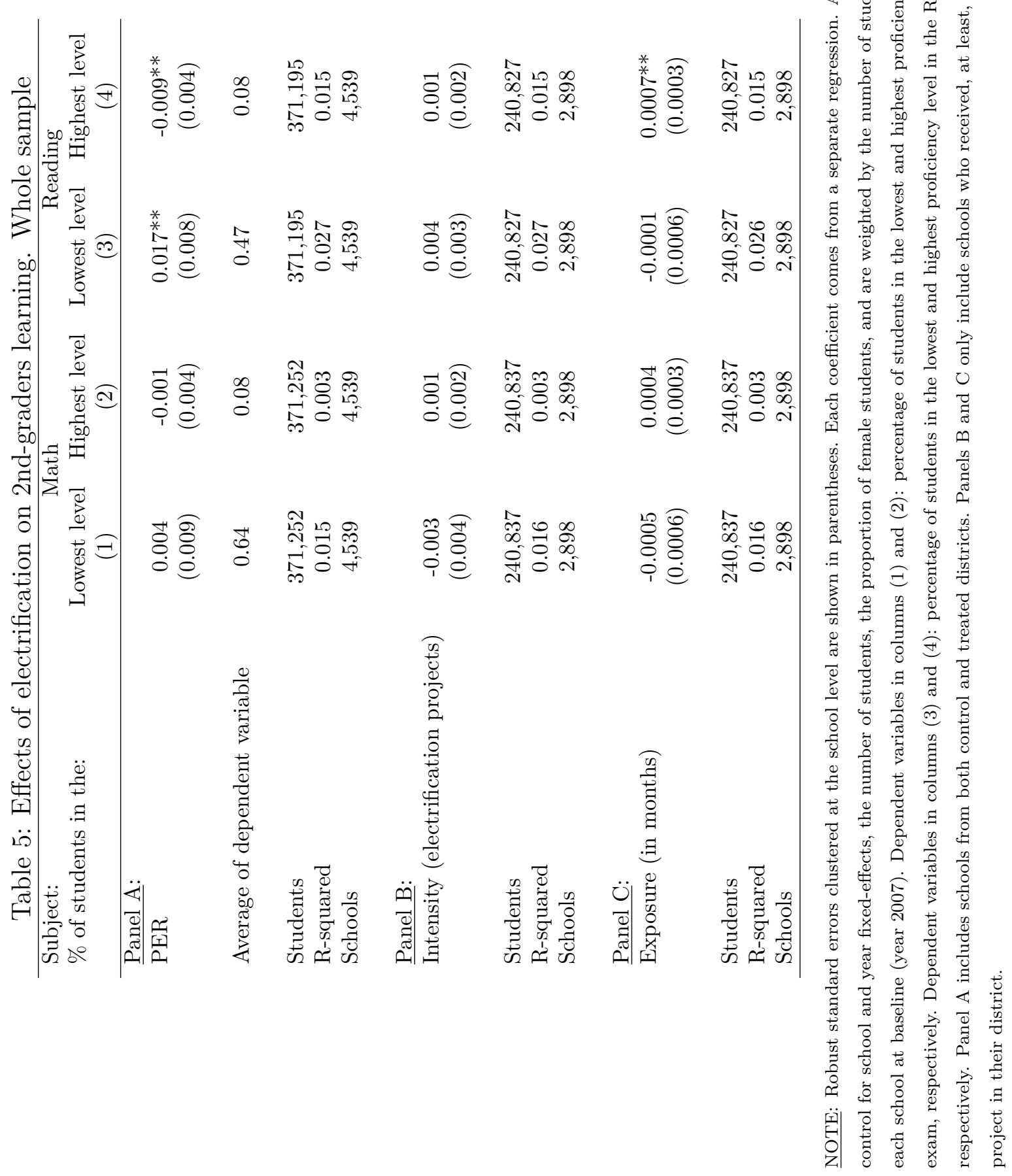




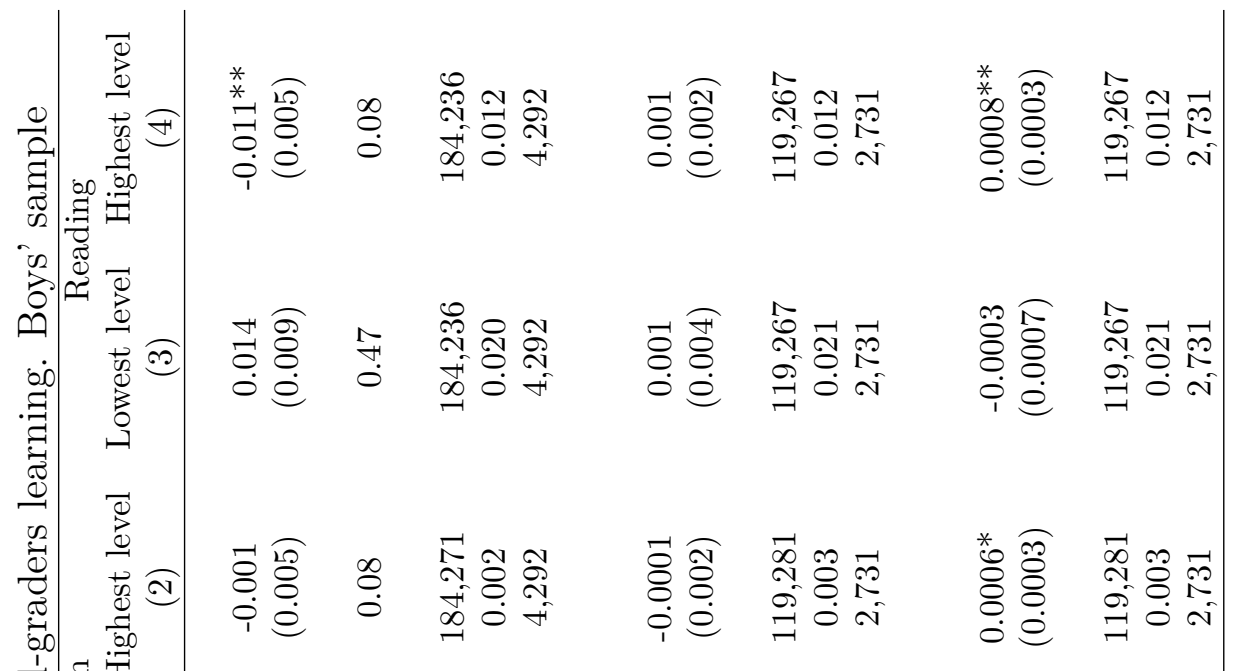

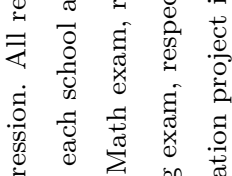

a

通事

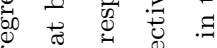

目

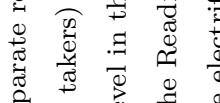

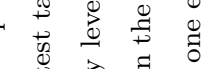

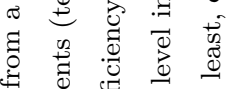

焉苛

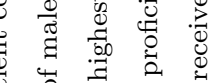

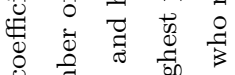

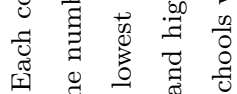

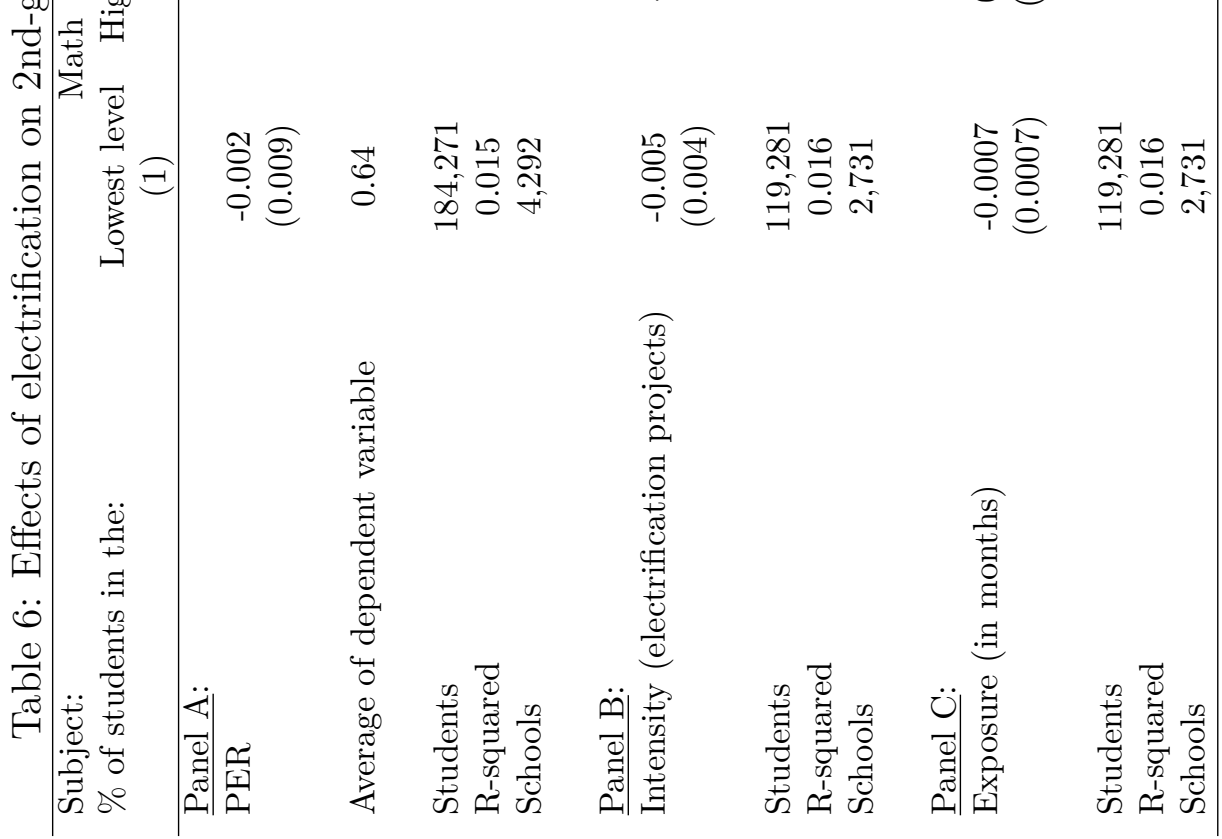

क

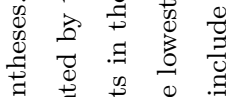

莺

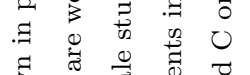

芌

离

उ

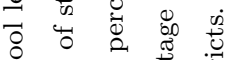

峁

ఫ

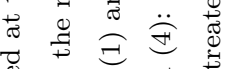

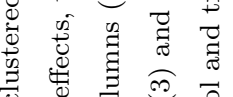

u

递芯青

离

उี चี

के $-\overrightarrow{0}$

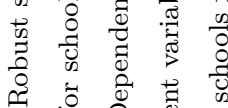

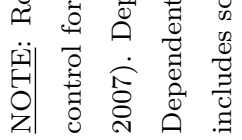


(1) III

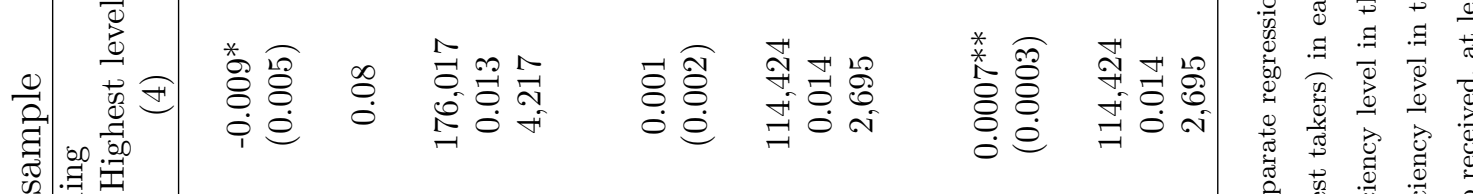

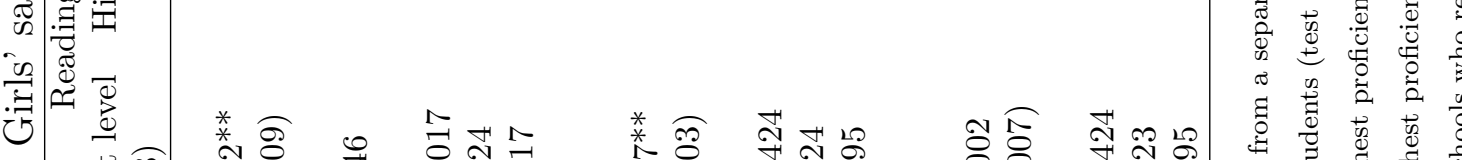

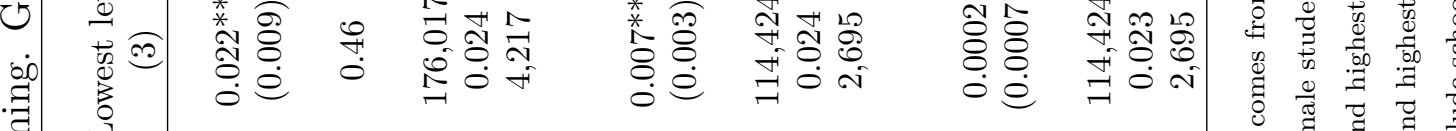

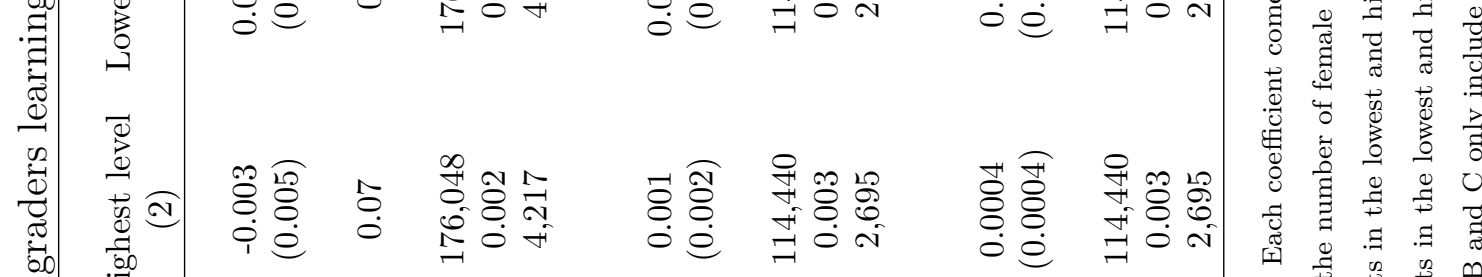

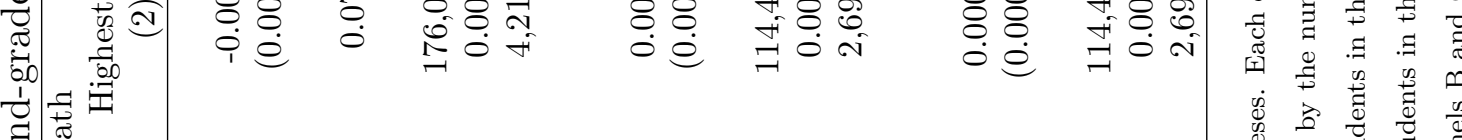

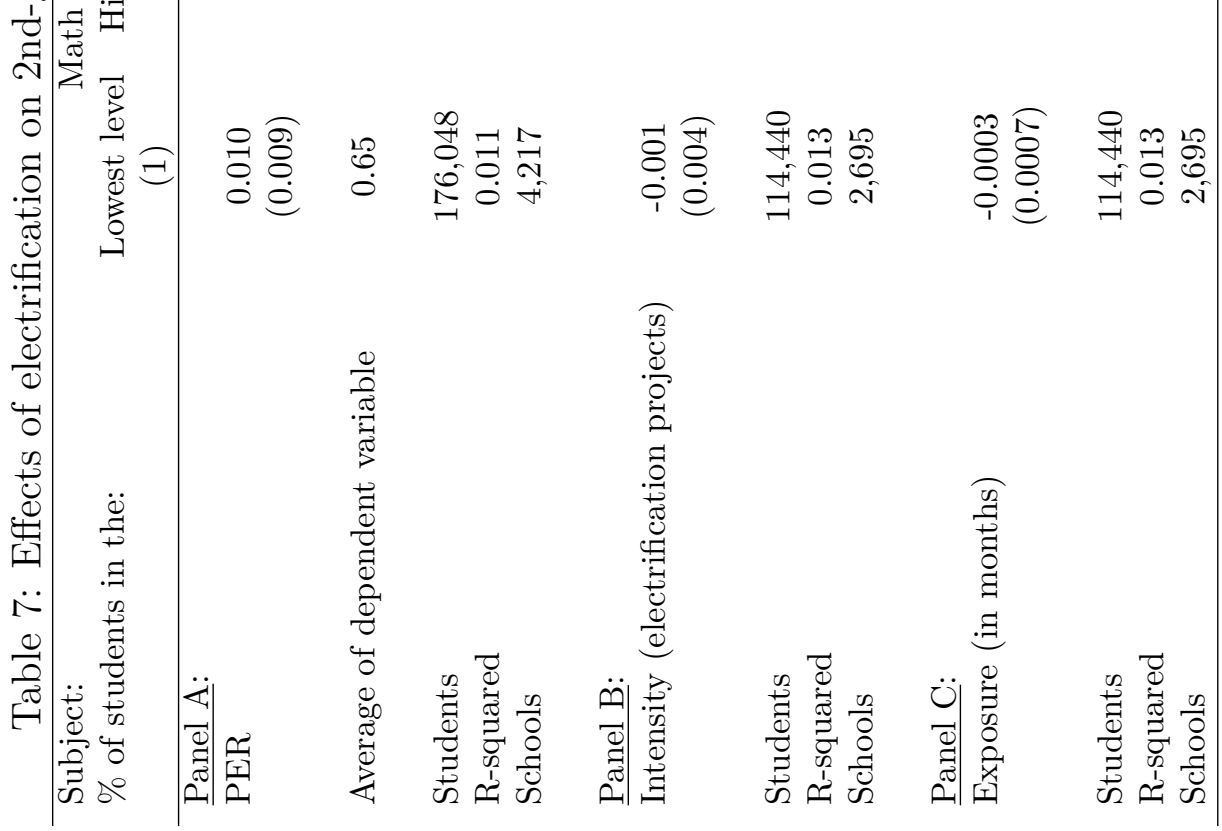
1 竞竞 


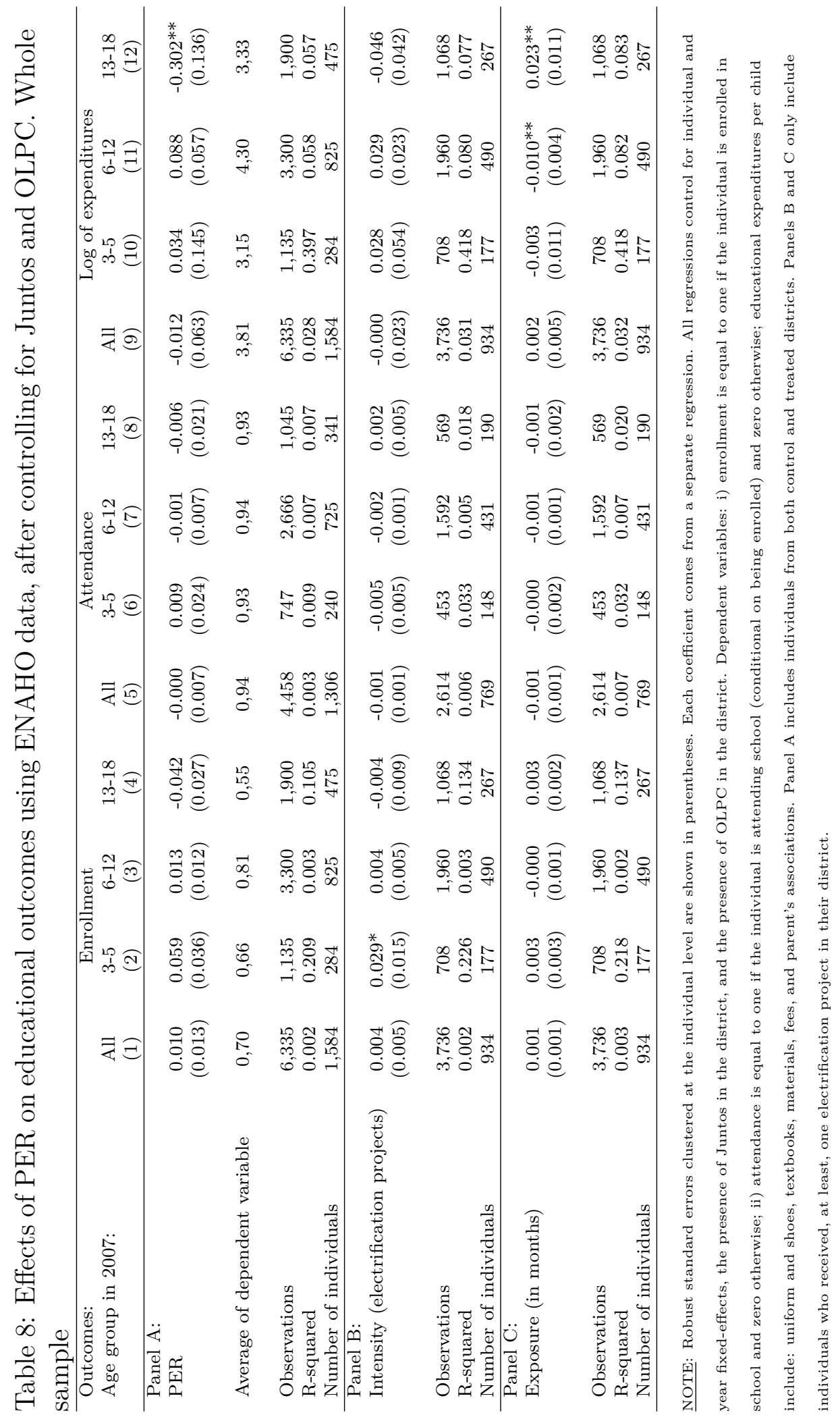




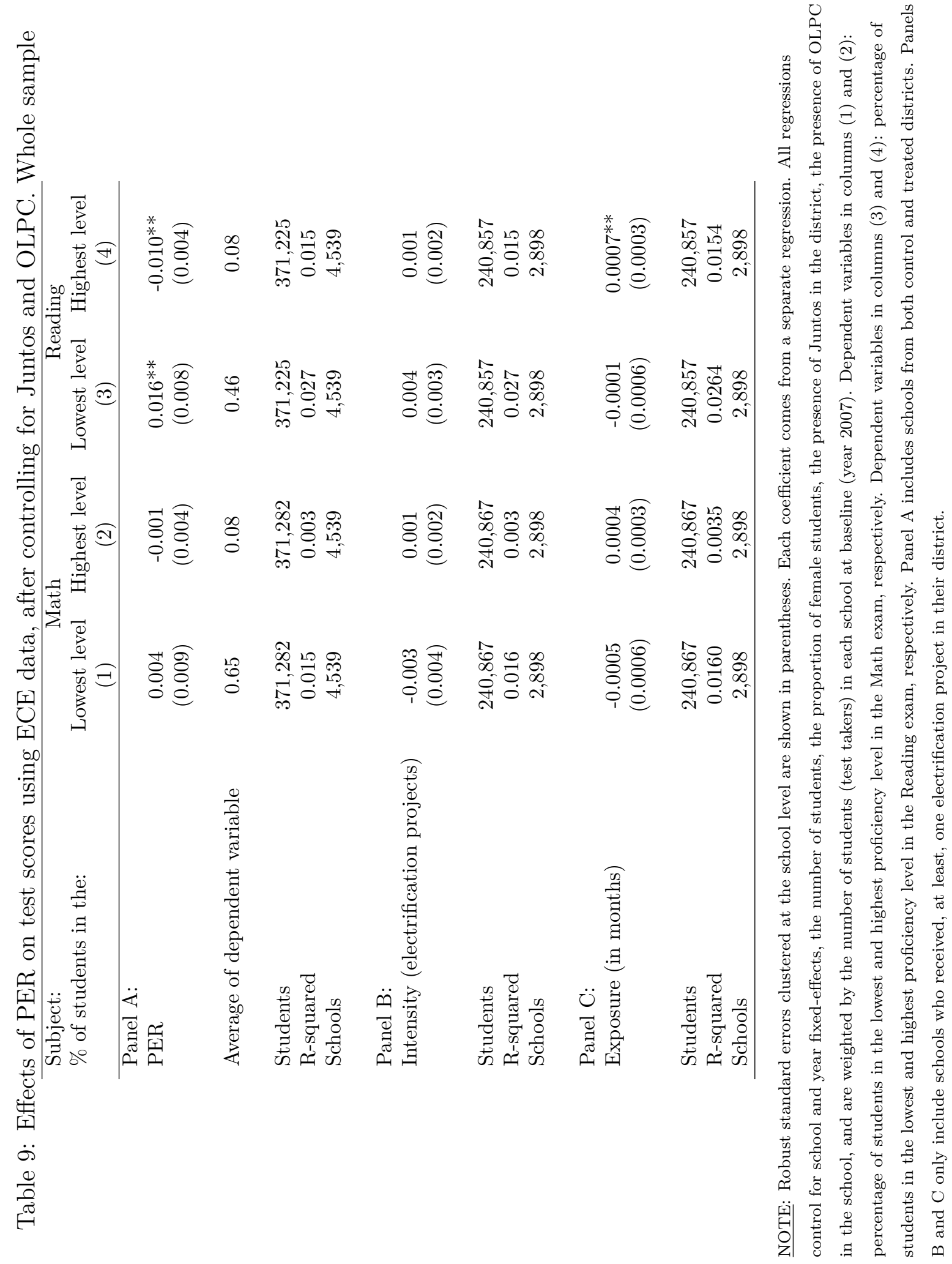




\section{APPENDIX}

Table A1: Effects of PER on access to electricity at home

\begin{tabular}{lccc}
\hline Dependent variable: & \multicolumn{3}{c}{ Access to electricity at home } \\
& $(1)$ & $(2)$ & $(3)$ \\
\hline PER & $0.062^{* * *}$ & & \\
& $(0.020)$ & & \\
Intensity (electrification projects) & \multicolumn{3}{l}{$0.037^{* * *}$} \\
& & $(0.007)$ & \\
Exposure (in months) & & & $0.005^{* * *}$ \\
& & & $(0.002)$ \\
Observations & 2,792 & 1,604 & 1,604 \\
R-squared & 0.086 & 0.161 & 0.146 \\
Number of households & 698 & 401 & 401 \\
\hline
\end{tabular}

NOTE: Robust standard errors clustered at the household level are shown in parentheses. Each coefficient comes from a separate regression. All regressions control for household and year fixed-effects. The dependent variable is equal to 1 if the household has electricity at home and 0 otherwise. Column 1 includes households from both control and treated districts. Columns 2 and 3 only include households who received, at least, one electrification project in their district. 
Table A2: Effects of PER on educational outcomes in pre-treatment period

\begin{tabular}{lccccccccc}
\hline & \multicolumn{3}{c}{ Enrollment } & \multicolumn{3}{c}{ Attendance } & \multicolumn{7}{c}{ Log of educ. expenditures } \\
Year: & 2004 & 2005 & 2006 & 2004 & 2005 & 2006 & 2004 & 2005 & 2006 \\
& $(1)$ & $(2)$ & $(3)$ & $(4)$ & $(5)$ & $(6)$ & $(7)$ & $(8)$ & $(9)$ \\
\hline \multirow{3}{*}{ PER } & 0.012 & 0.012 & -0.004 & -0.005 & -0.018 & -0.001 & -0.015 & 0.015 & -0.027 \\
& $(0.012)$ & $(0.012)$ & $(0.012)$ & $(0.017)$ & $(0.014)$ & $(0.014)$ & $(0.033)$ & $(0.033)$ & $(0.030)$ \\
& & & & & & & & & \\
Observations & 34,142 & 35,827 & 36,179 & 10,005 & 10,536 & 10,424 & 34,142 & 35,827 & 36,179 \\
R-squared & 0.000 & 0.000 & 0.000 & 0.000 & 0.001 & 0.000 & 0.000 & 0.000 & 0.000 \\
\hline
\end{tabular}

NOTE: Robust standard errors clustered at the district level are shown in parentheses. Each coefficient comes from a separate regression. Dependent variables: i) enrollment is equal to one if the individual is enrolled in school and zero otherwise; ii) attendance is equal to one if the individual is attending school (conditional on being enrolled) and zero otherwise; educational expenditures per child include: uniform and shoes, textbooks, materials, fees, and parent's associations. All regressions use ENAHO annual cross-sections, and restrict the analysis to individuals living rural districts at the time of the survey. 


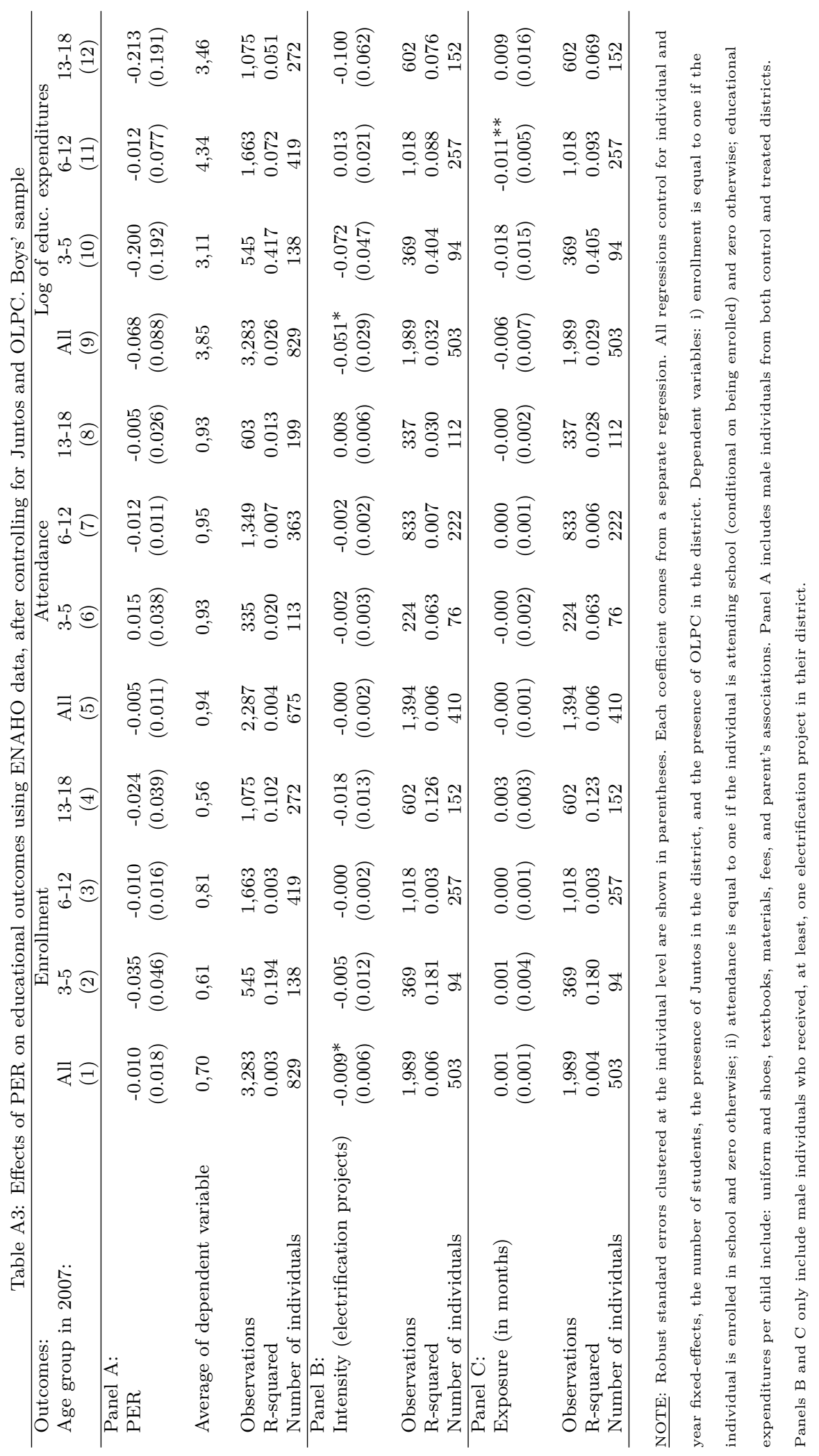




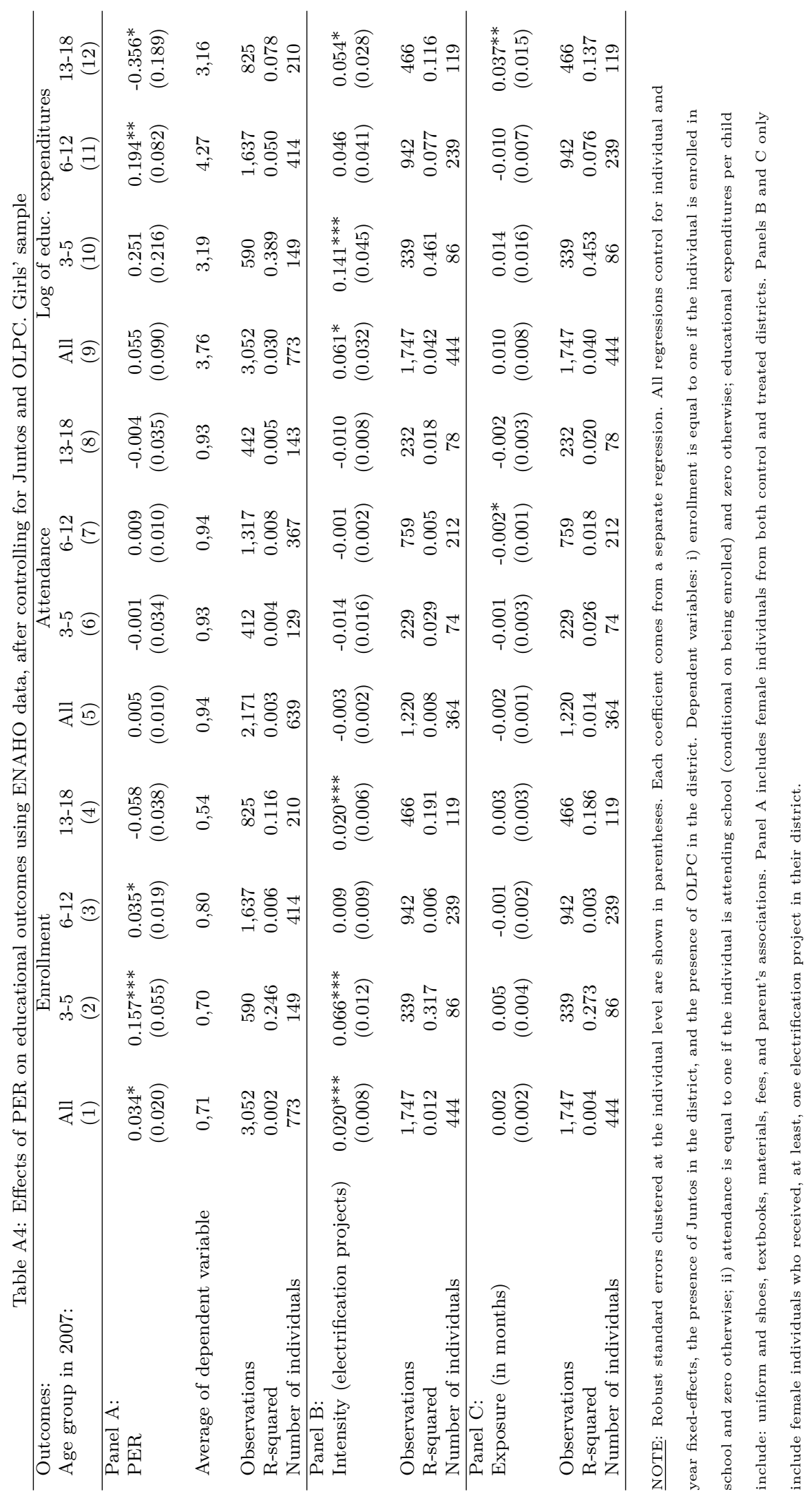




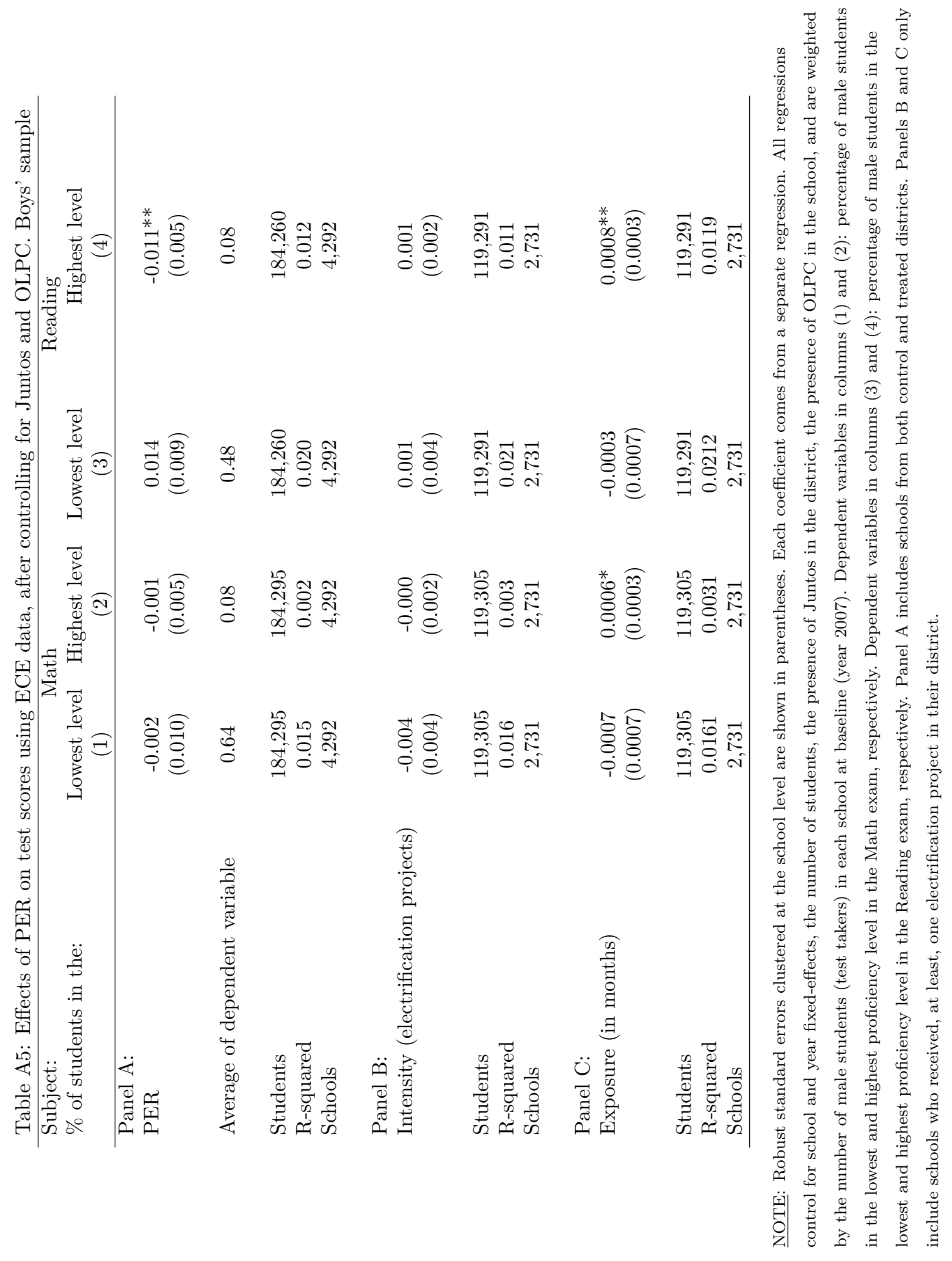



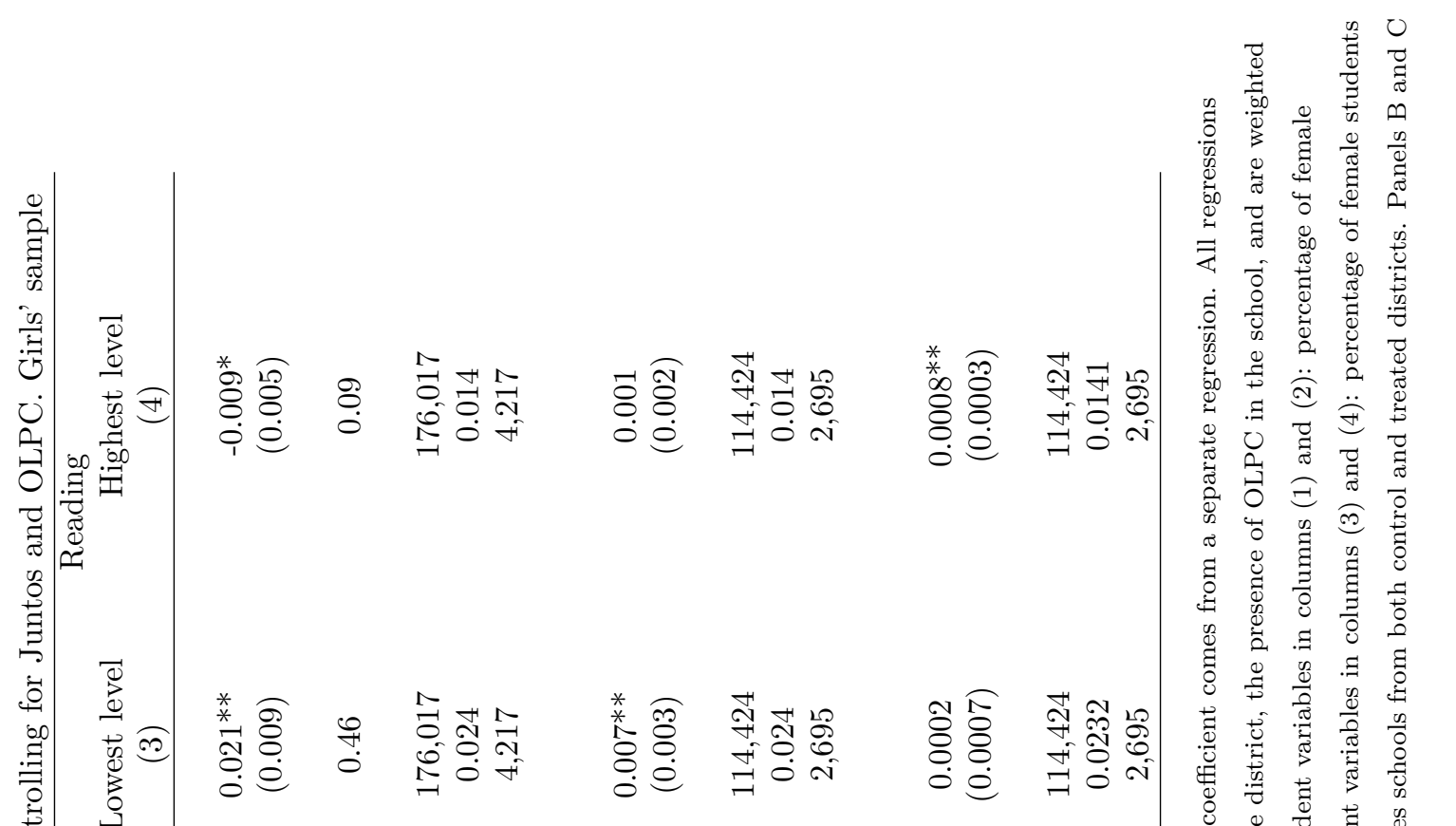

||

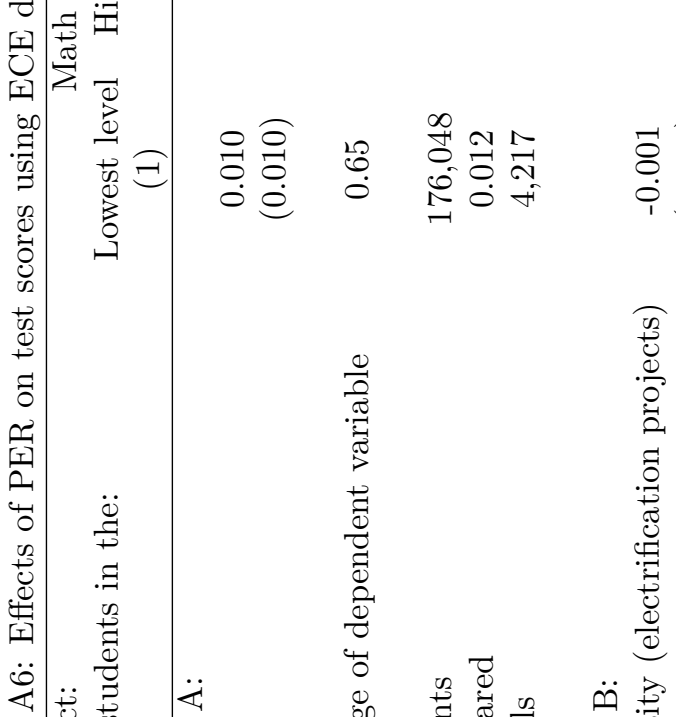

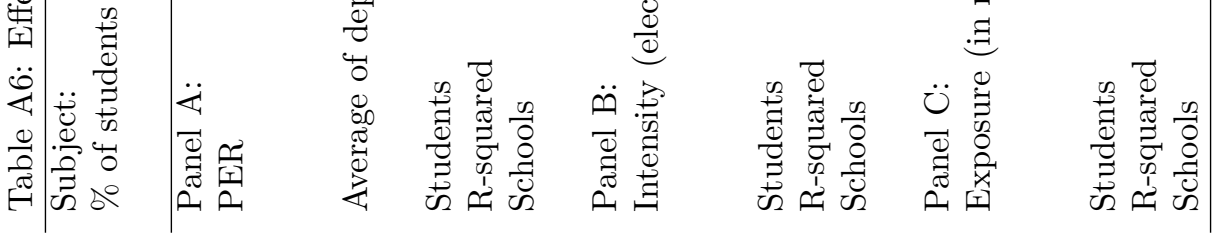

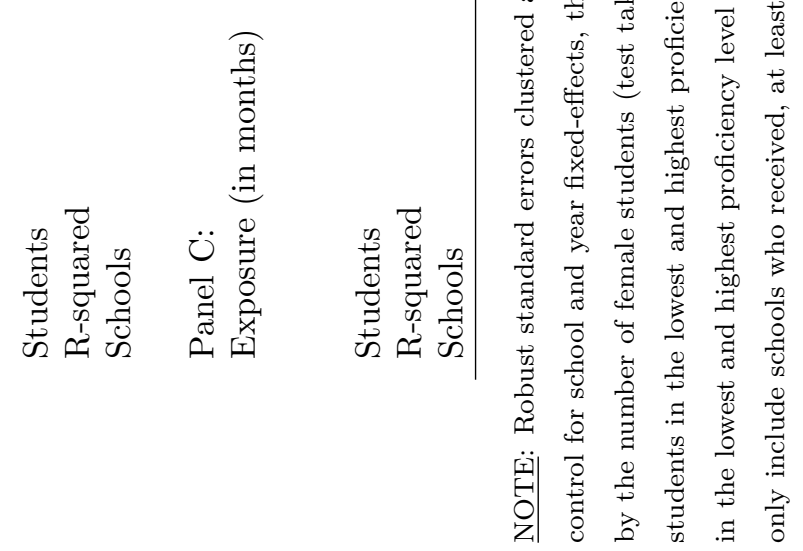

